\title{
A Cross-Sectional Analysis of the Muscle Strength, Spinal Shrinkage and Recovery During a Working Day of Military Police Officers
}

Francielle Holfinger

UTFPR: Universidade Tecnologica Federal do Parana

Andre Luiz Felix Rodacki ( $\Delta$ rodacki@ufpr.br)

Universidade Federal do Paraná https://orcid.org/0000-0002-4585-497X

Janny Miriam Tavares

UFPR: Universidade Federal do Parana

Milton Isac Fadel Neto

UTFPR: Universidade Tecnologica Federal do Parana

Anderson Caetano Paulo

UTFPR: Universidade Tecnologica Federal do Parana

Neil Edward Fowler

University of Salford

Cintia de Lourdes Nahhas Rodadki

UTFPR: Universidade Tecnologica Federal do Parana

Research

Keywords: Spinal Shrinkage, Low Back Pain, Workload

Posted Date: July 26th, 2021

DOl: https://doi.org/10.21203/rs.3.rs-736727/v1

License: (c) (i) This work is licensed under a Creative Commons Attribution 4.0 International License.

Read Full License 


\section{Abstract}

Background: Military personnel has a large prevalence of back, especially those involved in patrolling routines as they are required to wear heavy protective equipment. Patrolling includes long periods sustaining the protective equipment is sustained in a sitting either on or in a motor vehicle (motorcycle or car). Thus, understanding spinal loading of Military Police Officers (MPO) after patrolling by car (CAR; $n=14)$, motorcycle (MOT; $n=14)$, and administrative ( $A D M ; n=14)$ routines is relevant to establish preventive strategies.

Design: The torque of the trunk and working and anthropometric characteristics were assessed to explain and spinal loading using stature variation measures. Precise stature measures were performed before and after a $6 \mathrm{~h}$ journey (LOSS) and $20 \mathrm{~min}$ after a resting posture (RECOV). The isometric peak torque of the trunk extensor $\left(\mathrm{PTE} . \mathrm{BM}^{-1}\right)$ and flexor $\left(\mathrm{PTF}^{\mathrm{B}} \mathrm{BM}^{-1}\right)$ muscles were measured before the working journey.

Results: The LOSS was similar between CAR and MOT ( 4.8 and $5.8 \mathrm{~mm}$, respectively) after $6 \mathrm{~h}$ of patrolling. The ADM presented the lowest LOSS $(2.8 \mathrm{~mm} ; \mathrm{p}<0.05)$. No changes in RECOV between groups were observed $(p>0.05)$. Vibration may explain the greater spinal loading involved in CAR and MOT in comparison to the ADM. A GLM analysis revealed that only BMI was the only explanatory factor for stature loss. No independent variables explained RECOV. The ability of the trunk muscles to produce force did not influence LOSS or RECOV between groups.

Conclusions: MPOs involved in CAR or MOT patrolling may require greater post-work periods and strategies designed to reduce the weight of the protective apparatus to dissipate spinal loading. The external load used in patrolling is a relevant spinal loading factor.

\section{Highlights}

- BMI was the only independent variable associated with spinal loading

- Muscle strength of the trunk flexor and extensors was not identified as an attenuation factor.

- The spinal loading from patrolling by car or motorcycle was comparable but was lower than in administrative duties.

- No independent factors were able to explain stature recovery.

\section{Introduction}

Military Police Officers (MPO) are professionals subject to a substantial physical and mental health burden due to the constant exposure to stressful events. Studies have indicated a large prevalence of back pain (ranging from 28.7-54.9\%) among MPO [1]. The patrolling routines of MPO require the wearing of heavy protective equipment (vest, garrison belt, weaponry, handcuffs, etc.), weighing up to $14 \mathrm{~kg}$ [2]. Patrolling routines include long periods in which the weight of the protective equipment is sustained in a sitting position for prolonged periods either on or in a motor vehicle (motorcycle or car) or at an office 
desk. Benyamina Douma and colleagues (2018) reported a positive association between police officers who performed patrolling sitting by car and lower back discomfort. Although sitting is not a risk factor even in occupational sitting [3], prolonged periods of sitting have been suggested to increase the risk for LBP [4]. For instance, sitting for more than half of a workday in combination with whole body vibration, restrained or awkward postures increase the likelihood of having CLBP [5].

In addition to the sitting position and the overloading caused by the protective equipment, the vibration imposed by the vehicles while patrolling can further increase the LBP occurrence. It is known that vibration reduces the ability of the intervertebral discs to absorb the compressive forces of the spine due to an accelerated fluid loss [6, 7]. It has been shown that the capacity of the intervertebral discs to absorb and dissipate the loads applied on the spine depends on the amount of fluid in the nucleus pulposus [8]. As the fluid is expelled, a reduction in the ability to dissipate loads on the spine occurs. This change in the mechanical characteristics of the intervertebral discs causes overloading on other spinal structures that are not designed to bear loads $[1,6]$.

Changes in spinal length have been used to quantify the loads applied to the spine [9],[10]'[11]. The greater the loads applied to the trunk, the larger is the disk height loss, which causes a shortening of the spinal column (also called spinal shrinkage) [12]. When a load is removed, the intervertebral discs regain height and stature is recovered. Differences in the rate of recovery have been shown to differentiate those with and without LBP [13].

It has been demonstrated that the ability of the trunk flexor and extensor muscles to produce torque has been related to LBP [14]. It has also been proposed that some trunk flexor muscles can absorb and distribute loads - e.g., transverse abdominal [15] and improve spinal stability [16]. The weakness of the trunk extensor and flexor muscles has been associated with discomfort, loss of functional capacity, and LBP [17].

This study aimed (1) to quantify the mechanical spinal loading experiences by MPOs using spinal shrinkage as a criterion, in response to 6-hours of duty in a car, motorcycle or administrative functions and (2) to determine the relationship between the ability of the trunk muscles to generate torque and the amount of stature loss and recovery in MPO. It was hypothesized that patrolling performed using a motorcycle will produce greater spinal loading in comparison to the patrolling performed by car. It was also hypothesized that both patrolling activities (by car and motorcycle) impose a greater spinal loading than those involved in administrative tasks. Finally, it was hypothesized that a diminished ability to produce large torques by the trunk muscles - especially the trunk flexor muscles, will be associated with greater spinal loading and reduced recovery of stature.

\section{Materials And Methods}

Forty-two active male MPOs, who responded to an electronic call from their general headquarters, were selected to participate in the study. The following inclusion criteria were applied: a) aged 21 years or 
older; b) male; c) free from injuries or other physical issues that could impede physical testing; d) not being involved in sports of high performance; e) not using medicines that affect responses to tests (e.g., diuretic, anti-inflammatory, etc.).

The MPOs were invited to participate voluntarily, according to their availability, to cause minimal interference in their working routines. The participants were allocated in one of the three groups, according to their designation, patrolling by $\operatorname{Car}(C A R ; n=14)$, patrolling by Motorcycles (MOT; $n=14)$, and the Administrative (ADM; $n=14)$. Figure 1 shows the equipment used by the MPOs, as well as the usual positions and postures they adopt during their routines. The MOT group was selected because the protective gear is heavier than the other groups as they must transport most apparatuses attached to the body and are required to wear a helmet. Participants signed an Informed Consent Form that was previously approved by the Ethics Committee of the Federal Technological University of Paraná (number 3.264.257).

Participants attended two laboratory sessions. In the first visit, they were familiarized with the stature measurement protocol. The session lasted approximately $45 \mathrm{~min}$ until repeatable measurements of stature were obtained [18]. Participants were deemed as trained when a standard deviation (SD) of less than $0.5 \mathrm{~mm}$ was obtained in 10 consecutive measurements. The second visit was designed to quantify stature variations in response to the working activities performed by each group. The first measurements were conducted in the first hours of the day (between 7:00 and 8:00 AM) to reduce circadian variation effects [8]. Participants were weighted with and without protective equipment before adopting the Fowler's position for 20 minutes [12]. After this unloading period, participants stood for $1.5 \mathrm{~min}$ before mounting the stadiometer to allow soft tissue creep deformation of the lower limbs [19]. The first stature measurement was then recorded (PRE). The detailed description of the procedures in the stadiometer can be found elsewhere[18].

After completing their regular working routines (approximately $6 \mathrm{~h}$ ), participants' stature was again assessed, before (POST) and after (REC) a further 20 min of unloading in the Fowler's position. Stature loss was calculated as the difference between measurements taken before (PRE) and after (POST) the working journey (LOSS). Stature recovery (RECOV) was estimated as the difference of measures taken at the end of their working journey (POST) and after the 20 min of recovery.

After completing all stature measurements, participants were assessed for isometric peak torque. The peak torque of the trunk extensor (PTE) and flexor (PTF) muscles was defined as the highest torque using a calibrated load cell (EMG Systems, Brazil). Two minutes rest between attempts was allowed. The load cell was fixed to the trunk at the chest level and anchored on the ground by a steel cable and an adjustable Velcro strap. The peak torque was calculated by the product of the peak force $(\mathrm{N})$ and the distance from its fixation point to the center of the hip segment $(\mathrm{m})$ [20]. Participants were tested in the postures shown in Fig. 2. The peak torque of the trunk flexor and extensor muscles were normalized with respect to the body mass (PTF.BM ${ }^{-1}$ and PTE.BM ${ }^{-1}$, respectively). 
A standard statistical procedure (mean $\pm \mathrm{sd}$ ) was used to present a descriptive analysis. Normality and homogeneity were confirmed by the Levene and Shapiro Wilk tests, respectively. The age, BMI, the mass of the protective equipment the peak torques of the trunk extensor and flexor muscles, and the stature loss and recovery were compared using several one-way ANOVA, having the tasks performed by the MPOs (CAR, MOT, and ADM) as a grouping factor. The Bonferroni test was applied to identify where differences occurred. To determine the influence of the military patrolling activities (CAR and MOT) on stature loss (LOSS), a Univariate General Linear Model analysis was applied taking age, BMI, the weight of the protective equipment, and the peak torque of the flexor and extensor muscles as independent variables. A second Univariate General Linear Model analysis was applied to identify the influence of both patrolling activities (CAR and MOT) on the stature recovery (RECOV) using the same set of independent variables. The independent variables were selected after excluding other variables that showed a high correlation (>0.7) to avoid multicollinearity. The following variables were measured, but not included in the analysis: body weight, stature, waist circumference, sitting height, flexor/extensor torque ratio, and years of service. The statistical tests were performed using the SPSS Software, version 25.0, and the significance level was set as $p<0.05$.

\section{Results}

The physical characteristics of the participants are described in Table 1. As expected, the mass of the equipment of the administrative group was lighter than for the vehicle-based patrol groups. No differences were identified concerning the peak torque of the trunk between groups. The ADM experienced lower stature loss in comparison to the CAR and MOT groups. There were no statistical differences in stature loss between the CAR and MOT groups. No differences were identified in stature recovery between any of the three groups. 
Physical and work characteristics, muscular performance and stature variation (mean $\pm \mathrm{sd}$ ) of the MPO allocated in the car patrolling (CAR), motorcycle patrolling (MOT) and the administrative routines (ADM).

\begin{tabular}{|c|c|c|c|c|}
\hline & $\operatorname{CAR}(n=14)$ & MOT $(n=14)$ & $\operatorname{ADM}(n=14)$ & $\mathbf{P}$ \\
\hline Age (years) & $34.4 \pm 6.2$ & $33.8 \pm 3.0$ & $33.9 \pm 6.2$ & 0.958 \\
\hline Work time (years) & $9.6 \pm 5.4$ & $7.9 \pm 2.6$ & $10.4 \pm 4.7$ & 0.336 \\
\hline BM (Kg) & $81.2 \pm 9.0$ & $83.8 \pm 10.7$ & $85.1 \pm 12.2$ & 0.094 \\
\hline Stature (m) & $1.76 \pm 0.05$ & $1.75 \pm 0.05$ & $1.74 \pm 0.04$ & 0.675 \\
\hline BMI $\left(\mathrm{kg} \cdot \mathrm{m}^{-2}\right)$ & $26.6 \pm 0.6$ & $27.8 \pm 0.7$ & $27.6 \pm 0.9$ & 0.514 \\
\hline Equipment Mass (kg) & $8.3 \pm 0.4^{2,3}$ & $13.7 \pm 1.1^{1,3}$ & $4.2 \pm 1.0^{1,2}$ & $<0.001$ \\
\hline PTF.BM ${ }^{-1}\left(\right.$ N.m.BW $\left.{ }^{-1}\right)$ & $2.60 \pm 1.0$ & $2.52 \pm 0.6$ & $2.80 \pm 0.9$ & 0.685 \\
\hline PTE.BM-1 ${ }^{-1}$ (N.m.BW-1) & $1.70 \pm 0.6$ & $1.67 \pm 0.7$ & $1.65 \pm 0.4$ & 0.980 \\
\hline Stature Loss (mm) & $-4.80 \pm 1.97^{3}$ & $-5.82 \pm 2.14^{3}$ & $-2.80 \pm 1.48^{1,2}$ & $<0.001$ \\
\hline Stature Recovery (mm) & $1.95 \pm 1.86$ & $2.52 \pm 2.11$ & $2.36 \pm 1.69$ & 0.687 \\
\hline
\end{tabular}

The results of the general linear model analysis are presented in Table 2. The independent variables explained approximately $35 \%$ of the stature loss and $5 \%$ of the stature recovery. On the other hand, no independent variables were able to explain stature recovery after 20 minutes in the recovery position. 
Table 2

General Linear Model of the stature loss (LOSS) and recovery (RECOVERY) considering the independent variables for CAR and MOT groups.

\begin{tabular}{|c|c|c|c|c|c|c|c|c|}
\hline & & $\begin{array}{l}\text { Independent } \\
\text { Variables }\end{array}$ & Coefficient & $\begin{array}{l}\text { Std } \\
\text { Error }\end{array}$ & $\begin{array}{l}95 \% \\
\text { Inter. Cc }\end{array}$ & & $\mathrm{t}$ & p \\
\hline LOSS & MOT & AGE & .196 & .268 & -.422 & .814 & .731 & .486 \\
\hline & & $\mathrm{BMI}\left(\mathrm{kg} \cdot \mathrm{m}^{-2}\right)$ & .182 & .653 & 1.324 & 1.688 & .788 & .788 \\
\hline & & $\begin{array}{l}\text { Equipment } \\
\text { mass }(\mathrm{kg})\end{array}$ & -.172 & .159 & -.539 & .194 & -1.084 & .310 \\
\hline & & $\begin{array}{l}\text { PTF.BM-1 } \\
(\text { N.m.kg } \\
-1\end{array}$ & -.768 & 1.029 & -3.140 & 1.605 & -.746 & .477 \\
\hline & & $\begin{array}{l}\text { PTE.BM-1 } \\
\left(\text { N.m. } \mathrm{kg}^{-1}\right)\end{array}$ & .645 & 1.058 & -1.796 & 3.086 & .609 & .559 \\
\hline & & Intercept & -2.171 & 12.688 & -31.430 & 27.088 & -.171 & .868 \\
\hline & CAR & AGE & -.050 & .155 & -.407 & .307 & -.323 & .755 \\
\hline & & $\mathrm{BMI}\left(\mathrm{kg} \cdot \mathrm{m}^{-2}\right)$ & -.575 & .621 & -2.007 & 0.856 & -.927 & .381 \\
\hline & & $\begin{array}{l}\text { Equipment } \\
\text { mass }(\mathrm{kg})\end{array}$ & -.060 & .139 & -.262 & .381 & .428 & .680 \\
\hline & & $\begin{array}{l}\text { PTF.BM-1 } \\
(\text { N.m.kg-1) }\end{array}$ & -.513 & 1.381 & -3.698 & 2.672 & -.372 & .720 \\
\hline & & $\begin{array}{l}\text { PTE.BM-1 } \\
\left(\text { N.m. } \mathrm{kg}^{-1}\right)\end{array}$ & .503 & 1.480 & -3.917 & 2.911 & -.340 & .743 \\
\hline & & Intercept & 9.546 & 12.866 & -20.123 & 39.215 & .742 & .479 \\
\hline RECOVERY & MOT & AGE & -.299 & .324 & -1.046 & .449 & -.921 & .384 \\
\hline & & $\mathrm{BMI}\left(\mathrm{kg} \cdot \mathrm{m}^{-2}\right)$ & -.365 & .790 & -2.188 & 1.457 & -.462 & .656 \\
\hline & & $\begin{array}{l}\text { Equipment } \\
\text { mass }(\mathrm{kg})\end{array}$ & .088 & .192 & -.355 & .532 & .460 & .658 \\
\hline & & $\begin{array}{l}\text { PTF.BM }{ }^{-1} \\
\left(\text { N.m.kg }{ }^{-1}\right)\end{array}$ & -1.087 & 1.245 & -3.958 & 1.784 & -.873 & .408 \\
\hline & & $\begin{array}{l}\text { PTE.BM-1 } \\
\left(\text { N.m.kg }{ }^{-1}\right)\end{array}$ & -.161 & 1.281 & -3.114 & 2.793 & -.126 & .903 \\
\hline CAR - Loss: & $2=0.16$ & Adjusted $R^{2}=-$ & 3; MOT Loss & $\mathrm{R}^{2}=0.43$ & Adjustec & ${ }^{2}=0.083$ & & \\
\hline CAR - Reco & $: \mathrm{R}^{2}=$ & 450; Adjusted & 106; MOT & covery: & $=0.149$ & Ictad & -0.383 & \\
\hline
\end{tabular}




\begin{tabular}{|c|c|c|c|c|c|c|c|}
\hline & $\begin{array}{l}\text { Independent } \\
\text { Variables }\end{array}$ & Coefficient & $\begin{array}{l}\text { Std } \\
\text { Error }\end{array}$ & \multicolumn{2}{|c|}{$95 \%$} & $t$ & $\mathbf{p}$ \\
\hline & Intercept & 18.678 & 15.354 & -16.729 & 54.085 & 1.216 & .258 \\
\hline \multirow[t]{6}{*}{ CAR } & AGE & .161 & .118 & -.111 & .434 & -1.719 & .124 \\
\hline & BMI $\left(\mathrm{kg} \cdot \mathrm{m}^{-2}\right)$ & .093 & .474 & -1.000 & 1.187 & .197 & .849 \\
\hline & $\begin{array}{l}\text { Equipment } \\
\text { mass }(\mathrm{kg})\end{array}$ & .089 & .107 & -.156 & .335 & .838 & .426 \\
\hline & $\begin{array}{l}\text { PTF.BM } \\
(\text { N.m.kg } \\
\end{array}$ & 2.164 & 1.055 & -.269 & 4.598 & 2.151 & .074 \\
\hline & $\begin{array}{l}\text { PTE.BM-1 } \\
\left(\text { N.m.kg }{ }^{-1}\right)\end{array}$ & -1.059 & 1.131 & -3.668 & 1.550 & -.936 & .377 \\
\hline & Intercept & -16.901 & 9.831 & -39.573 & 5.770 & -1.719 & .124 \\
\hline \multicolumn{8}{|c|}{ CAR - Loss: $\mathrm{R}^{2}=0.167 ;$ Adjusted $\mathrm{R}^{2}=-0.353 ;$ MOT Loss: $\mathrm{R}^{2}=0.435 ;$ Adjusted $\mathrm{R}^{2}=0.083$} \\
\hline \multicolumn{8}{|c|}{ CAR - Recovery: $R^{2}=0.450$; Adjusted $R^{2}=0.106$; MOT Recovery: $R^{2}=0.149 ;$ Adjusted $R^{2}=-0.383$} \\
\hline
\end{tabular}

\section{Discussion}

This study was designed to determine the changes in stature (loss and recovery) in response to $6 \mathrm{~h}$ of different working journeys performed by patrolling and administrative MPOs. It also aimed to identify if the stature variations (loss and recovery) are related to the ability of the trunk flexor and extensor muscles to generate force and anthropometric and working characteristics. Stature loss was noted for all working conditions but was greatest in those MPOs involved in patrolling activities, irrespective of the vehicle type (car or motorcycle).

Stature variation measures have been used as an index of spinal loading in a range of tasks [21]. It has been shown that extended sitting causes stature reductions [22], which act as a high-risk factor for LBP [23]. The stature loss in the administrative MPOs $(2.80 \mathrm{~mm})$ was smaller than that observed in other studies (from 5.6 to $6.3 \mathrm{~mm}$ ) that have analyzed stature changes while sit-stand and sitting during a regular office workday $[24,25]$. In contrast, others have demonstrated comparable stature losses during a short period of sitting of 15 minutes (from 2.95 to $3.47 \mathrm{~mm}$; [26]) and $1 \mathrm{~h}$ (from 1.5 to $2.6 \mathrm{~mm}$; [27]). Possibly, differences in office chair types and the amount of sit-stand activity, as well as other body movements during the working day, may have clouded comparisons between studies. It has been demonstrated that some movements of the body may help to recover stature [28]. The chair type [28] and the use of backrests [29], the lack of instructions regarding sit-stand ratio [24] and the uncontrolled movements performed during the workday (e.g., intermittent hyperextensions; [30]) may have also played a role. 
The lower stature change observed in the administrative MPOs in comparison to the patrolling MPOs can be partially explained by the fact that they are less overloaded (50-77\% less load) and not exposed to vibration effects. Indeed, the reduced load they sustain during their workdays is the lowest in comparison to that imposed by the weight of the mandatory protective equipment used in patrolling activities. It is known that the greater the load, the greater is the stature loss [30], which may have a superimposed effect of vibration. Magnusson and colleagues [29] reported that 5 minutes of sinusoidal vibration exposure causes greater stature loss when compared to regular sitting (i.e., without vibration). It has been evidenced that workers exposed to vibration are more likely to experience muscle fatigue and reduce the mechanical properties of soft tissues, which may make them more prone to injuries [31]. It is especially concerning because the low frequencies caused by the vehicle's tires hitting the road is in the resonant range of the low back $(5-7 \mathrm{~Hz})$ and may cause further discomfort when the vehicle speed increases [32]. Therefore, the compounded effect of vibration and overloading may explain the larger stature changes in MPOs after a working journey involving vehicle patrolling in comparison to those involved in administrative tasks.

Although the MPOs that patrolled using a motorcycle were subject to approximately $40 \%$ greater loads due to protective equipment (i.e., $16 \%$ of BM; see Fig. 1), the stature loss was comparable to that observed while patrolled by car. Generally, MPOs on motorcycle patrol are recommended to dismount for 15 minutes each hour of the workday. Changing postures during the working journey may have reduced the magnitude of the stature loss and resulted in comparable losses to that imposed while patrolling by car. The spinal overloading from while patrolling by car may have suffered the influence of the backrest inclination. Magnusson and colleagues [29] reported that seats with a backrest tilted at $120^{\circ}$ cause less stature loss in comparison to seats without a backrest. On the other hand, sitting without a backrest causes a pelvic retroversion, which changes the physiological curve of the spine and modifies the compressive load distribution [33].

Wearing heavy protective apparatus may have also fatigued the muscles as the working day unfolds. It is known that muscle's ability to generate and sustain torque is essential to enhance and provide stability [34]. Besides, the muscles surrounding the spine are known to support and stabilize the spinal column may have their protective functions reduced. Abdominal pressure increases are associated with the activation of the abdominal flexor muscles and have been thought to be beneficial by producing spinal unloading during extension efforts - especially by the transverse abdominal [35]. It is also possible that the continuous activation of the muscles to increase the stiffness of the spine and improve stability may have caused an unceasing loading effect. These compressive forces may have increased spinal loading and, consequently, more substantial stature losses.

The ability of the trunk extensor and flexor muscles to generate torque was not relevant to reduce the spinal loading, irrespective of the patrolling vehicle (car or motorcycle). The borderline (non-significant) influence of the trunk extensors to generate torque in the stature loss may indicate that MPOs with greater strength may experience larger compressive loads on the intervertebral discs and so experience a considerable stature loss. The ability to produce large amounts of force was not a protective component 
to reduce spinal loading as measured by stature loss. Additional studies involving larger samples and more uniform working loads are required to test these arguments.

On the other hand, several studies have indicated that fast and prompt responses are more relevant to stabilize the spinal column than large amounts of torque [16]. Thus, peak torque may not be the most relevant component to stabilize the spine, and other parameters (e.g., muscle activation ratio and the rate of torque development) may be more significant. Exercise interventions designed to improve muscle strength and neuromuscular coordination are considered as the most effective treatments to prevent and to reduce LBP [36]. Indeed, some investigations aimed to reduce low back pain have demonstrated that exercises performed with low muscle activation (i.e., unlikely to promote substantial strength and torque gains) are effective in increasing spinal stabilization and to reduce chronic low back pain [37]. Therefore, the ability to produce large amounts of torque failed to explain stature loss in MPOs.

On the other hand, BMI was the only significant variable to explain stature loss. It has been suggested that individuals with greater BMIs (i.e., with higher body mass) sustain a "chronic" loading condition and are more prone to experience adverse effects [38]. Even though the weight of the protective apparatus was not a significant factor, it may have amplified the chronic loading condition and increased the stature loss. The weight of the protective equipment of both patrolling groups was approximately three times greater than the additional load of the group involved in administrative tasks (i.e.,13.3\% vs. $4.9 \%$ BW).

Therefore, the acute loading imposed by the protective apparatus may have caused an additive loading in both patrolling groups, which explains the smaller stature loss experienced by the group involved in administrative tasks. It is interesting to note that the univariate analysis failed to identify the task performed by the MPOs as a relevant factor. It can be speculated that stature loss was similarly influenced during the patrolling tasks, as both groups (MOT and CAR) showed comparable reductions. Thus, from a mechanical point of view, patrolling by CAR or MOT produced similar spinal loadings. Thus, it seems that efforts to reduce the spinal loading by decreasing body mass and the protective apparatus are a plausible solution to avoid spinal overloading, as the peak torque of the trunk flexor and extensor muscles were not identified as explanatory factors. Studies designed to analyze the way several apparatuses are transported (handcuffs, ammunition, gun, etc.) are required. Indeed, it has been demonstrated that the overload caused by the bulletproof vest can cause muscular fatigue, especially on the side the gun is transported. Thus, future studies to redesign the way MPOs carry additional apparatuses are required, as well as alternative materials to reduce the weight of the bulletproof vest without diminishing its protective effect.

At the end of the working day, the 20 minutes period of unloading was sufficient to allow a partial restoration of the stature loss in all groups. The ADM group recovered $77 \%$ of the initial stature, with MOT $40 \%$ and CAR $46 \%$ recovery. Although the relative recovery was lower for the motor vehicle groups, the absolute change in stature was similar, indicating an equivalent rate of recovery regardless of stature loss. The univariate analysis failed to identify task differences as a relevant factor to recovery between the patrolling groups. A reduced rate of stature recovery has been shown by Rodacki and colleagues [13] 
and Healey and colleagues [10] to be associated with low back pain. The absence of any difference in recovery rates between groups is in line with expectations as existing low back pain was an exclusion criterion for the study. The findings do demonstrate that MPOs who have been on patrol in a car or motorcycle need to allow a greater period after the work to recover stature loss.

This study has some limitations, and the reader should bear them in mind while interpreting the results. The first refers to the limited number of participants that may have reduced the power of the analysis and impeded establishing a more detailed group comparison. However, the number of participants is comparable to similar studies. As the results were gathered on participants while fulfilling their normal daily activities, it was not possible to control the nature of the activities and movements performed during the working routines (e.g., sit-stand ration, hydration). The posture assumed while sitting in the car or the motorcycles were not controlled, although they represent that real working conditions. It was not possible to separate the effects of the weight of the equipment and vibration, which requires other studies. Finally, differences in patrolling routines (mainly due to the weight of the protective equipment) may have influenced the results, as participants were subjected to different spinal loadings. Other studies applying a more uniform spinal loading is required to confirm if muscle strength presents a protective effect.

\section{Conclusion}

This study quantified stature changes in Military Police Officers exposed to administrative and car and motorcycle patrolling activities. The results revealed that stature loss depends on task, and these effects may be due to both vibration and external load. Effects of external loads are additionally supported by the finding of an effect of BMI. The stature recovery was similar between groups and was not explained by age, $\mathrm{BMI}$, the ability of the trunk muscles to generate torque. The differences in the task performed by the patrolling groups also failed to explain stature loss and recovery. The degree of recovery was, however, lower for those from the vehicle-based patrol groups as a consequence of the greater stature lost during the working day. The understanding of the mechanisms related to stature loss and recovery may help to restructure the working routines and the weight of the required protective equipment. Studies devoted to redesigning the way the load of the equipment are required.

\section{Declarations}

\section{- Ethics approval and consent to participate}

The Ethical Approval was granted by the University Ethics Committee of the Federal Technological University of Paraná under the number 3.264.257. It is stated in the methods section

\section{- Consent for publication}

The authors of the manuscript read the document in full and are in agreement with its contents and provided consent for Publication 


\section{- Availability of data and materials}

The data may be made available upon request. The materials applied in the study are described in the methods section.

\section{- Competing interests}

Authors declare no competing interests

\section{- Funding}

The study did not receive funding

\section{- Authors' contributions}

All authors actively participated in the experiment in which Dr André Rodacki, Anderson Paulo and Cintia Rodacki guided the study, provided all facilities and equipment for its development and designed the experimental approach. Janny Tavares, Milton Fadel Neto and Francielle Holfinger participated in data collection and data processing. Neil E. Fowler helped with data analysis and in the discussion of the manuscript. All authors helped in the discussion, statistical analysis, drafting and revising the manuscript. All authors are aware of the content of the manuscript.

\section{- Acknowledgements}

Nothing to disclose

\section{References}

1. Benyamina Douma N, Coté C, Lacasse A. Occupational and Ergonomic Factors Associated With Low Back Pain Among Car-patrol Police Officers. Clin J Pain. 2018;34:960-6.

2. Konitzer LN, Fargo M V., Brininger TL, Lim Reed M. Association between Back, Neck, and Upper Extremity Musculoskeletal Pain and the Individual Body Armor. J Hand Ther. 2008;21:143-9.

3. Swain CTV, Pan F, Owen PJ, Schmidt H, Belavy DL. No consensus on causality of spine postures or physical exposure and low back pain: A systematic review of systematic reviews. J Biomech. 2020;102.

4. Pope MH, Goh KL, Magnusson ML. Spine Ergonomics. Annu Rev Biomed Eng. 2002;4:49-68.

5. Lis AM, Black KM, Korn H, Nordin M. Association between sitting and occupational LBP. Eur Spine J. 2007;16:283-98.

6. Bovenzi M. M BOVENZI A Longitudinal Study of Low Back Pain and Daily Vibration Exposure in Professional Drivers. 2009;584-95.

7. Burström L, Nilsson T, Wahlström J. Whole - body vibration and the risk of low back pain and sciatica: a systematic review and meta - analysis. 2013; 
8. Reilly T, Tyrrell A, Troup JDG. Circadian variation in human stature. Chronobiol Int. 1984;1:121-6.

9. Rabal-Pelay J, Cimarras-Otal C, Alcázar-Crevillén A, Planas-Barraguer JL, Bataller-Cervero AV. Spinal shrinkage, sagittal alignment and back discomfort changes in manufacturing company workers during a working day. Ergonomics [Internet]. 2015; Available from:

http://dx.doi.org/10.1016/j.jileo.2015.07.023

10. Healey EL, Fowler NE, Burden AM, McEwan IM. The influence of different unloading positions upon stature recovery and paraspinal muscle activity. Clin Biomech. 2005;20:365-71.

11. Nahhas Rodacki CL, Luiz Felix Rodacki A, Ugrinowitsch C, Zielinski D, Budal da Costa R. Spinal unloading after abdominal exercises. Clin Biomech. 2008;23:8-14.

12. Fowler NE, Rodacki ALF, Rodacki CD. Changes in stature and spine kinematics during a loaded walking task. 2006;23:133-41.

13. Rodacki CL, Fowler NE, Rodacki AL, Birch K. Stature loss and recovery in pregnant women with and without low back pain. Arch Phys Med Rehabil. 2003;84:507-12.

14. McGill SM, Grenier S, Kavcic N, Cholewicki J. Coordination of muscle activity to assure stability of the lumbar spine. J Electromyogr Kinesiol. 2003;13:353-9.

15. Chang D, Healey R, Snyder A, Sayson J, Macias B, Coughlin D, et al. Lumbar spine paraspinal muscle and intervertebral disc height changes in astronauts after long-duration spaceflight on the International Space Station. Physiol Behav. 2016;41:1917-24.

16. Hodges PW, Richardson CA. Inneficient Muscular Stabilization of the Lumbar Spine Associated With Low Back Pain. Spine (Phila Pa 1976). 1996;21:2640-50.

17. Freeman MD, Woodham MA, Woodham AW. The Role of the Lumbar Multifidus in Chronic Low Back Pain: A Review. PM R. 2010;2:142-6.

18. Rodacki CLN, Fowler NE, Rodacki ALF, Birch K. Repeatability of measurement in determining stature in sitting and standing postures. Ergonomics. 2001;44:1076-85.

19. Foreman TK, Linge K. The importance of heel compression in the measurement of diurnal stature variation. Appl Ergon. 1989;20:299-300.

20. Rodacki CLN, Rodacki ALF, Pereira G, Naliwaiko K, Coelho I, Pequito D, et al. Fish-oil supplementation enhances the effects of strength training in elderly women. Am J Clin Nutr. 2012;95:428-36.

21. McGill SM, Van Wijk MJ, Axler CT, Gletsu M. Studies of spinal shrinkage to evaluate low-back loading in the workplace. Ergonomics. 1996;39:92-102.

22. Van Deursen LL, Van Deursen DL, Snijders CJ, Wilke HJ. Relationship between everyday activities and spinal shrinkage. Clin Biomech. 2005;20:547-50.

23. Bakker EW., Verhagen A., Van Trijffel E, Lucas C, Koes BW. Spinal Mechanical Load as a Risk Factor for Low Back Pain: A systematic review of prospective cohort studies. Spine (Phila Pa 1976). 2010;34:281-93.

24. Gao Y, Cronin NJ, Pesola AJ, Finni T. Muscle activity patterns and spinal shrinkage in office workers using a sit-stand workstation versus a sit workstation. Ergonomics. 2016;59:1267-74. 
25. van Dieen̈ JH, Creemers M, Draisma I, Toussaint HM, Kingma I. Repetitive lifting and spinal shrinkage, effects of age and lifting technique. Clin Biomech. 1994;9:367-74.

26. Phimphasak C, Swangnetr M, Puntumetakul R, Chatchawan U, Boucaut R. Effects of seated lumbar extension postures on spinal height and lumbar range of motion during prolonged sitting. Ergonomics. 2016;59:112-20.

27. Kingma I, van Dieën JH. Static and dynamic postural loadings during computer work in females: Sitting on an office chair versus sitting on an exercise ball. Appl Ergon. 2009;40:199-205.

28. Van Dien JH, Hermans V, De Looze MP. Effects of dynamic office chairs on trunk kinematics, trunk extensor emg and spinal shrinkage. Ergonomics. 2001;44:739-50.

29. Magnussson M, Almqvist M, Broman H, Pope M, Hansson T. Measurement of Height Loss Durimng Whole Body Vibrations. J Spinal Disord. 1992;5:198-203.

30. Magnussson M, Pope MH. Body height changes with hyperextension. Clin Biomech. 1996;11:236-8.

31. Hoy J, Mubarak N, Nelson S, Sweerts De Landas M, Magnusson M, Okunribido O, et al. Whole body vibration and posture as risk factors for low back pain among forklift truck drivers. J Sound Vib. 2005;284:933-46.

32. Hostens I, Ramon H. Descriptive analysis of combine cabin vibrations and their effect on the human body. J Sound Vib. 2003;266:453-64.

33. Nachemson A, Elftrom G. Intravital dynamic pressure measurements in lumbar discs. A study of common movements, maneuvers and exercises. Scand J Rehabil Med. 1970;1:1-40.

34. Grenier SG, McGill SM. Quantification of Lumbar Stability by Using 2 Different Abdominal Activation Strategies. Arch Phys Med Rehabil. 2007;88:54-62.

35. Stokes IAF, Gardner-Morse MG, Henry SM. Abdominal muscle activation increases lumbar spinal stability: Analysis of contributions of different muscle groups. Clin Biomech [Internet]. Elsevier Ltd; 2011;26:797-803. Available from: http://dx.doi.org/10.1016/j.clinbiomech.2011.04.006

36. Bigos SJ, Holland J, Holland C, Webster JS, Battie M, Malmgren JA. High-quality controlled trials on preventing episodes of back problems: systematic literature review in working-age adults. Spine J. 2009;9:147-68.

37. Hubley-Kozey CL, Vezina MJ. Muscle activation during exercises to improve trunk stability in men with low back pain. Arch Phys Med Rehabil. 2002;83:1100-8.

38. Rodacki ALF, Fowler NE, Provensi CLG, Rodacki CDLN, Dezan VH. Body mass as a factor in stature change. Clin Biomech. 2005;20:799-805.

\section{Figures}




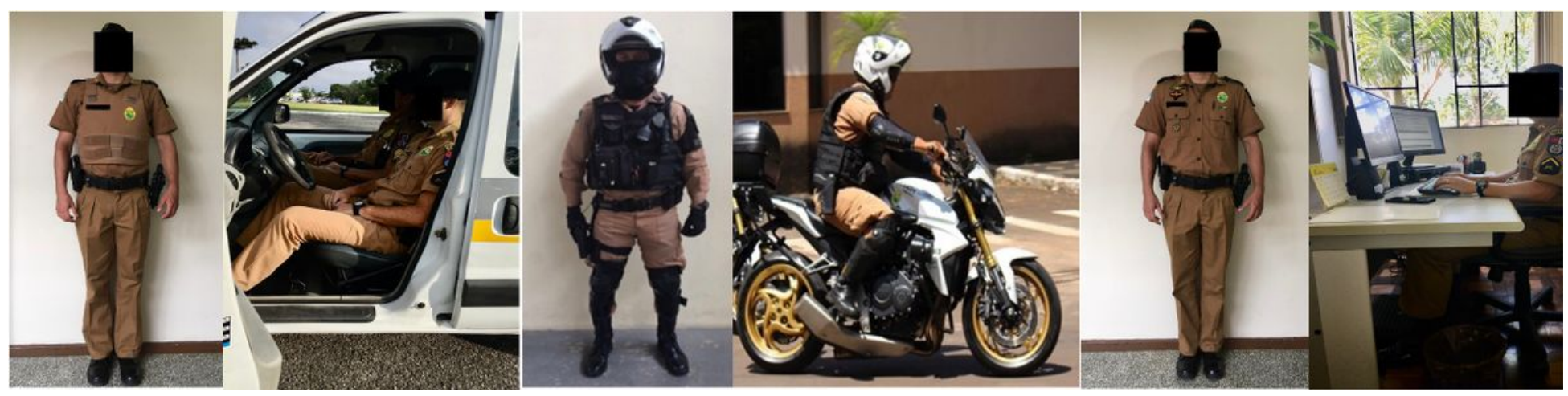

\section{Figure 1}

The equipment used by the MPOs; a) patrolling by car (CAR), b) patrolling by Motorcycles (MOT) and c) Administrative (ADM) as well as the positions they adopt during their routines.

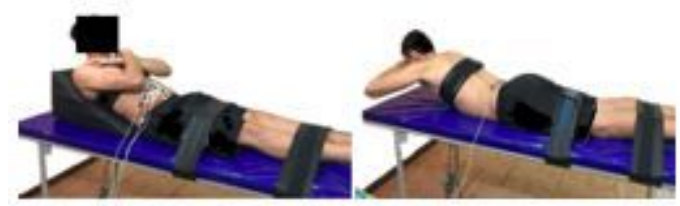

Figure 2

The postures used to determine the peak torque of the trunk flexor (PTF) (left panel) and extensor muscles (PTE) (right panel). 